\title{
Designing for Online Collaborative Consumption: A study of sociotechnical gaps \& social capital
}

\author{
Ali Gheitasy ${ }^{1}$, José Abdelnour Nocera ${ }^{1}$, Bonnie Nardi ${ }^{2}$, Dimitrios Rigas ${ }^{1}$ \\ ${ }^{1}$ University of West London, London, UK \\ \{Ali.Gheitasy, Jose.Abdelnour-Nocera, \\ Dimitrios.Rigas\} @uwl.ac.uk \\ ${ }^{2}$ University of California, Irvine, California, USA \\ Nardieics.uci.edu
}

\begin{abstract}
This study attempts to investigate sociotechnical gaps in online collaborative consumption (OCC) to improve user experience and provide better design requirements. A new approach is proposed to evaluate usability and sociability of the OCC communities. The formation of social capital within OCC will also be studied to gain insights into design requirements. Due to its features as a community where OCC takes place, ETSY will be the focus of this study.
\end{abstract}

Keywords: Online Collaborative Consumption (OCC), Computer Supported Cooperative Work (CSCW), sociotechnical gap, social capital, usability, sociability and user experience (UX).

\section{Introduction}

Constant changes in human's social life lead to a gap between their requirements and the existing technological capabilities. The main challenge for CSCW (Computer Supported Cooperative Work) is to identify and ameliorate this sociotechnical gap. The problems of CSCW have been distinguished by Ackerman [1] as:

- Generalizability from small groups to a general population (social sciences)

- Predictability of affordances (HCI)

- Applicability of new technological possibilities (computer science)

Online communities that enable collaborative consumption are more than just ordinary websites. They allow users not only to consume information but also to provide and contribute to the content within a wide range of topics. They evolve in accordance with how individuals communicate, with the aid of a website or software within their social interactions. Design principles of online communities are guided by their purpose, policies, selection of technology, designing usability, and supporting sociability [1]. Sociability refers to providing "a state of being sociable" within online community, where users find it satisfying to interact with each other to achieve their goals [2]. 
Therefore, to approach the sociotechnical gap, it is essential to understand individuals' interaction and collaboration in online communities, the technologies supporting them, and the usability and sociability of these technologies. This could be done by investigating online communities that enable the individuals to consume collaboratively. In doing this, we investigate users' experience, behaviours and their needs, in order to better support OCC. This research aims to answer these questions: What are the sociotechnical gaps in technologies supporting OCC? How can we better support design of OCC platforms on identifying these gaps? How is social capital formed in OCC? How to evaluate online collaborative communities?

\section{Online Collaborative Consumption}

OCC enables individuals to interact with each other and to exchange information, knowledge, experience, materials, support, etc. Earlier OCC mainly involved in sharing files, photos, videos and knowledge, while nowadays it engages other areas of our everyday life. Collaborative consumption provides substantial environmental benefits by increasing efficiency and reducing the waste of resources by encouraging reselling and reusing old or unwanted materials [3]. It amends our consumption habits regarding not only what to consume but also how to consume. Open collaborative projects such as open software and Wikipedia as a part of OCC inspire the collective actions, which serve the need of individuals and at the same time provide a sense of belonging to a community. It enhances the "Crowdsourcing", which is distribution of tasks between a group of networked individuals or community to solve a problem with collective intelligence and action [4]. The collaboration and interaction in the heart of OCC enables individuals to be active citizens of society, enhances their associational activities, accumulates collective actions and trust, helps to make friends, and increases their social capital.

\section{Social Capital}

Social capital has been defined by The World Bank [5] as "the norms and social relations embedded in social structures that enable people to coordinate action to achieve desired goals". Putnam [6] defined social capital as trust, network structures, and norms that promote cooperation among actors within a society for their mutual benefits. Therefore, it can be concluded that social capital consists of a number of core features such as: trust, associational activities and civic norms, which are closely related to the principles of OCC.

Different types of networks or groups lead to different types of social capital, which bring different advantages for individuals. Bonding social capital includes homogenous groups of individuals and close networks (sharing similar circumstances, situations or life experiences). It accumulates trust, creates shared funds, increases exchange of favour, mutual support, mobilizes solidarity, and helps to share limited resources. However, it limits the information flow and resource exchange due to its' 
closed networks nature [7]. Bridging social capital consists of heterogeneous groups of individuals and sparse networks (with different circumstances, situations or life experiences). It provides more informational benefits [8], due to more open and sparse network that provides actors with less redundant connections in order to easily gain non-redundant information and have new opportunities. These two types generated where there are individual ties exist. Next paragraph discusses the collective or non-tie social capital.

Social capital can also be generated within circumstances where no individual ties exist, such as online communities where individuals help each other without knowing one other. Occasionally these individuals can get to know each other after social exchange and keep in touch subsequently. Online communities enable individuals to engage in social action to achieve collective goals, facilitate social capital within social relationships, trust, and reciprocity [9-12].

Jiang and Carrol [13] theorized that most social capital studies use the SNA (social network analysis) to define and visualize community or social network. It emphases on individual gains by using an egocentric perspective and ignores the collective side of the social capital. In addition to SNA, other validated measurement scale such as Williams's survey [14] also measures individual bridging and bonding and overlook the collective side of the social capital. Therefore, this study intends to investigate the differences in the formation of social capital at collective (non-tie) and individual level, and also to discover how ties and networks can be generated within collective social capital.

\section{$4 \quad$ Methodology}

As one of the case studies, ETSY is the data gathering platform for this research. It is an online marketplace and community that connects buyers with craftsmen to buy and sell handmade, vintage and crafts supplies. Its diverse community features include Teams, Forums, Live chat, Offline events and online workshops. ETSY enable members with common interests to collaborate, exchange information, experience and support, and also to meet with each other. It is an appropriate platform for this study since it provides diverse collaborative tools and community features, and also it is a growing community with 30 million members in 200 countries [15]. Next, the data gathering methods for this research will be discussed.

Standard usability evaluation methods evaluate users' performance in specified tasks in a controlled context, which is not convenient for evaluating the online communities. As Preece et al. [1] argues, they are useful, but inadequate for evaluating online communities since they do not address sociability. Besides in many online communities, sociability overshadows usability. A study of Facebook users by Hart et al. [16] revealed that usability testing does not elicit all the significant aspects of social web use, such as self-expression or social pleasure. They also found that users are less 
concerned about the bad usability of the system when there are enjoyable aspects that compensate the usability inadequacies. In addition, they suggest a more holistic approach to evaluation in order to support the new design guidelines of modern day social websites. Likewise Malinen and Ojala [17] claim that usability heuristics concentrate on a task-oriented approach and exclude social and "hedonistic" characteristics. Regarding collaborative systems evaluation, Araujo et al. [18] identify four crucial elements; including group context, usability, collaboration, and cultural impact. These elements as part of the evaluation process distinguish the group and work context, usability strengths and weaknesses, collaboration capabilities, and investigate the impact of the system over time. Furthermore, Antunes et al. [19] suggest an "eclectic approach" in evaluation of collaborative systems to cover several factors, including the individual and group characteristics within social and organizational contexts, to assess positive and negative effects of technology.

Therefore, we can conclude that a holistic approach is needed to focus on sociability components to assess purpose, protocols, and codes of behavior in addition to usability and user experience to evaluate the ease of use and user satisfaction. A combined methodological framework is proposed in this paper to evaluate OCC, ETSY in this case. Ethnography complements predictive evaluation by considering the user at the centre of the evaluation by accompanying them in interview and surveys. (Figure 1) 


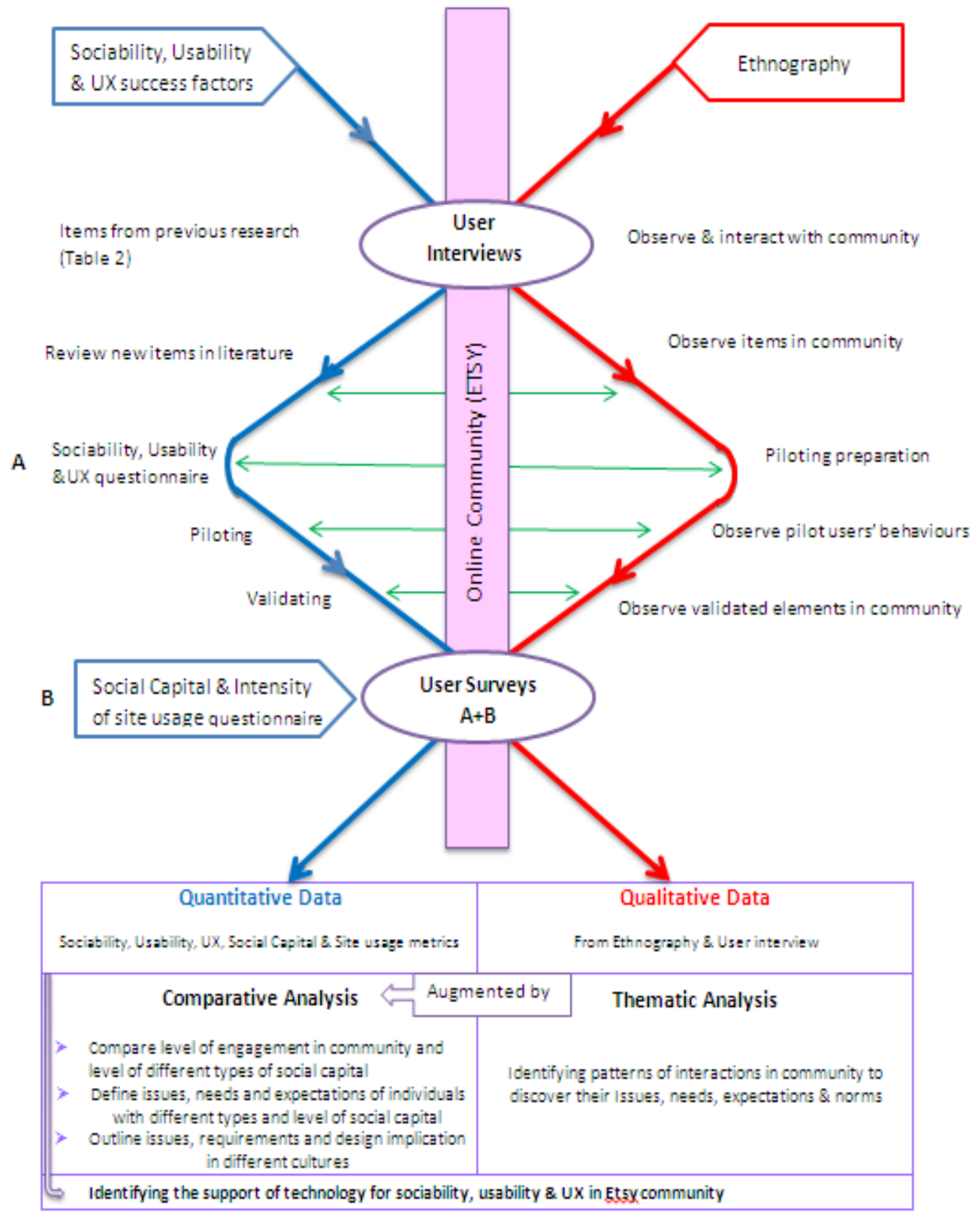

Figure 1: User Centred Evaluation 


\subsection{Ethnography}

Ethnography and qualitative research methods are recommended by Preece et al. [2] as suitable approaches for studying social interaction and sociability. It provides a naturalistic interpretation and understanding of human behavior within cultures and communities by providing descriptions of social structures, behaviors, symbols, and language [20]. This method helps to analyze and understand the community's interaction within their 'textual social discourse' [21]. This approach helps to understand the culture of the online community from an insider's point of view. The holistic nature of this approach, based on contextualized findings, allows the researcher to develop a deep understanding of how issues related to sociability are developed and are expressed within online community. However, we should bear in mind that for an indepth understanding of a community and its norms and interactions, a long term commitment is essential. In addition, it is not guaranteed to be able to gain access to the relevant and suitable type of data, within existing social interaction contents. Therefore in order to increase the validity and reliability of ethnography and qualitative research methods, they need to be complemented with other methods. One of the methods which could complement ethnography can be predictive evaluation.

\subsection{Predictive Evaluation}

Predictive evaluation makes use of heuristics to predict the usability problems [22]. These heuristics are useful guidelines in eliciting the usability issues. But these guidelines are not always accurate in testing the interactive interfaces, such as online communities. Furthermore, like other methods, they need to be customized specifically for evaluating sociability [23]. This approach has also been criticized regarding the validity of the gathered data, as the evaluators are substitute users and it does not involve real users in the process [24]. Drawing the heuristics from the perspectives of real users of community could be a good basis for evaluating the success of the online community. Nonetheless, it has been shown that users are often not very consistent in self-reporting [25]. Thus, using the appropriate heuristics to develop surveys could be helpful in probing users in reporting their issues, needs and expectation of their online communities. Ethnography helps to understand the culture, norms and behaviours [26] of ETSY community members and facilitates selection of the relevant success factors. Considering the nature of ETSY community, the appropriate success factors or heuristics including sociability, usability and user experience (UX) drawn from previous literatures. (Table 2)

Table 2

\begin{tabular}{|l|l|l|}
\hline Constructs & \multicolumn{1}{|c|}{ Items } & Source \\
\hline \multirow{2}{*}{$\begin{array}{l}\text { Social rela- } \\
\text { tionship }\end{array}$} & S1: Network creation (e.g. individuals with similar interest) & {$[27,2]$} \\
\cline { 2 - 3 } & S2: Face to face communication (e.g. offline meetings \&events) & {$[29,3]$} \\
\cline { 2 - 3 } & S3: Dynamic interaction (e.g. verbal, gestural \& emoticons) & {$[1]$} \\
\hline
\end{tabular}




\begin{tabular}{|c|c|c|}
\hline & S4: Social \& emotional support & [31] \\
\hline \multirow{3}{*}{ Reciprocity } & S5: Information exchange & [32] \\
\hline & S6: New product \& innovation & [32] \\
\hline & S7: Achieving a collective goal (knowledge creation/ problem solving) & [33] \\
\hline \multirow{6}{*}{$\begin{array}{l}\quad \text { Trust } \\
\text { (Privacy \& } \\
\text { Identity) }\end{array}$} & S8: Different level of anonymity (limit of privacy) & [34] \\
\hline & S9: Persistent identity & [35] \\
\hline & $\begin{array}{l}\text { S10: Members profiles and pictures (creativity in self- } \\
\text { presentation \& identity construction) }\end{array}$ & {$[36,37]$} \\
\hline & S11: Transparency (e.g. exposing identity of content providers) & [34] \\
\hline & S12: Clear establishing of self-goals for the community & [34] \\
\hline & S13: Trust creation features (e.g. reputation model) & [38] \\
\hline \multirow{6}{*}{$\begin{array}{l}\text { Content crea- } \\
\text { tion / } \\
\text { member con- } \\
\text { tribution }\end{array}$} & S14: Social recognition \& self-expression & {$[39,41]$} \\
\hline & S15: Fast \& informal interaction (commenting \& rating contents) & [40] \\
\hline & S16: Rewards \& recognition for contribution & {$[39,4]$} \\
\hline & S17: Feedback to motivate (public \& private) & [39] \\
\hline & S18: Volunteerism & {$[27,4]$} \\
\hline & S19: Self-satisfaction & [43] \\
\hline \multirow{3}{*}{$\begin{array}{l}\text { Purpose, pol- } \\
\text { icies \& proce- } \\
\text { dures }\end{array}$} & S20: Relevant rules of behaviour \& clear displayed policies & {$[1]$} \\
\hline & S21: Different members' roles (e.g. contributor and reader) & [44] \\
\hline & S22: Suitability \& functionality of content & {$[28]$} \\
\hline \multirow{3}{*}{$\begin{array}{c}\text { Information } \\
\text { design \& } \\
\text { presentation }\end{array}$} & SU23: Advanced \& filter search for content & {$[23]$} \\
\hline & SU24: Easy information obtaining & [45] \\
\hline & SU25: Discussion board organization & {$[1]$} \\
\hline \multirow{4}{*}{$\begin{array}{l}\text { technology } \\
\text { Support }\end{array}$} & $\begin{array}{l}\text { SU26: Subgroup formation (facilitate interaction \& discussion in differ- } \\
\text { ent subtopics) }\end{array}$ & {$[27,46]$} \\
\hline & SU27: Awareness tools (e.g. calendaring tool for meeting) & $\begin{array}{l}\text { Ethnog- } \\
\text { raphy }\end{array}$ \\
\hline & $\begin{array}{l}\text { SU28: Social presence tools(e.g. status info, camera connection, IM, } \\
\text { graphical presentation of activity \&avatar) }\end{array}$ & [47] \\
\hline & SU29: Other tools (chat, mailing list, UseNet news, etc.) & [48] \\
\hline \multirow{3}{*}{ Navigation } & U30: Consistent \& easy navigation & \multirow[t]{3}{*}[1,22]{} \\
\hline & U31: Intuitive layout & \\
\hline & U32: Visibility of site (what is going on in the site...) & \\
\hline \multirow{2}{*}{ User control } & U33: Feeling in charge of system & \multirow[t]{2}{*}[1,22]{} \\
\hline & U34: Error prevention \& correction & \\
\hline \multirow{2}{*}{ Reliability } & U35: Access to system always to be available & [49] \\
\hline & U36: Easy to remember search sequence & {$[44,50]$} \\
\hline
\end{tabular}

(Guide: Sociability: S / Usability: U / UX: S1-S14, S22 / Collective Social capital: S1 S13) 


\subsection{User Interviews}

In this stage user interviews co-validate the above success factors or heuristics (Table 2) from the perspectives of the real users of the ETSY community. The users will be asked to rate the importance of each item by looking back on their experience using ETSY. The rating is based on 5 scale ranking, the 1 and 2 rated items will be omitted and the 3, 4, and 5 scored will be considered. They can also recommend new items. This will contribute to developing a questionnaire incorporating sociability, usability and UX constructs. In addition, the ethnography which will be carried out in the meantime, will help in developing the questionnaire by observing its' elements in the community. The final questionnaire will be piloted with the users and validated afterwards to ensure their suitability for the community.

\subsection{User Surveys}

Once the final questionnaire is validated, the user surveys will be carried out. The users will be asked to rank the support of the community for each item based on Likert scale. Ethnography will also help to finalize the questionnaire and to observe the user members' behaviours. In this stage, previously validated items for social capital and intensity of usage will be added to this questionnaire.

\subsection{Intensity of Site Usage}

To determine the association between the usage of OCC communities and social capital; the intensity of the usage and social capital should be measured. Intensity of site usage will be measured by using a survey in which some items will be adapted from Ellison et al's Facebook Intensity scale [28] with modified wordings to match the context of this study. This survey and interviews assess the individual's behavior and measure the engagement in OCC community. They obtain the number of friends, the amount of time spent on a day, the extent of emotional connection and the level of integration within daily activities. Defining the intensity of site usage can help in answering the formation of different social capital and possible association between the amount of site usage and the increase of social capital.

\subsection{Social Capital Measures}

The study of social capital will be based on three dimensions including bridging, bonding and collective. The bridging and bonding dimension will be measured by a survey adapted from the existing scales Williams [15]. He has developed and validated the survey, based on Putnam's [51] criteria to measure individuals' online social capital. According to the focus of the study some of the questions also will be modified. 


\subsection{Collective (non-tie) Social Capital Measures}

As discussed earlier in the literature, social relationships, trust and reciprocity are the main construct for the social capital in the online communities. These constructs will be measured within the sociability elements of the final questionnaire (Table 2, Items: S1-S13).

Results of User surveys generate quantitative data which will be augmented by qualitative data from ethnography and interviews.

\section{Contribution of the Study}

We hope that the results of this study will shed light on sociotechnical gaps by revealing the different social and cultural needs, requirements, and technological affordances to support OCC. The goal is to develop a framework to evaluate and support the design of OCC by revealing individuals' difficulties, needs and expectations in using OCC community. Learning about formation of social capital could inform design requirements to support development of the right type of social capital within OCC. Findings from implementing this framework will inform new and enhanced design features to support OCC in increasing collective and non-tie social capital. Furthermore they will expose the individuals' collaboration and social interaction patterns in and across different cultures.

\section{References}

1. Preece, J., Abras, C. and Maloney-Krichmar, D. "Designing and evaluating online communities: research speaks to emerging practice," International Journal of Web Based Communities, vol. 1, pp. 2-18, 2004.

2. Phang, C. W. Kankanhalli, A. and Sabherwal, R. "Usability and sociability in online communities: A comparative study of knowledge seeking and contribution." Journal of the Association for Information Systems, vol. 10, pp. 721-747, 2009.

3. Botsman, R. and Rogers, R. "What's mine is yours: how collaborative consumption is changing the way we live." London: Collins. 2011.

4. Howe, J. "Crowdsourcing: Why the Power of the Crowd is Driving the Future of Business." 2008.

5. The World Bank, "World Development Report. Washington, DC: The World Bank." 1985.

6. Putnam, R. "Bowling alone: America's declining social capital." J. Democr. 1995.

7. Portes, A. "Social capital: Its origins and applications in modern sociology." 1998.

8. Burt, R. S. "The social capital of structural holes. New Directions in Economic Sociology.” Russell Sage Foundation, 2001. 
9. Blanchard, A. L. and Horan, T. "Social capital and virtual communities." 1998.

10. Chaboudy, R. and Jameson, P. "Connecting families and school through technology." Book Report 20 (2), 52-57. 2001.

11. Hampton, K. N., "Grieving for a lost network: Collective action in a wired suburb." 2003.

12. Iriberri, A. "Building online community: An action research project." In Proceedings of the Eleventh Americas Conference on Information Systems. N. Romano, Ed. AIS, Atlanta, GA. 2005.

13. Jiang, H. and Carroll, J, M. "Social Capital, Social Network and Identity Bonds: A Reconceptualization.” ACM 978-1-60558-601. University Park, Pennsylvania, USA. 2009.

14. Williams, D. "On and off the Internet: Scales for social capital in an online era." Journal of Computer-Mediated Communication, 11(2), article 11. 2006.

15. Etsy. "Notes from Chad: 30 Million Members Strong." [ONLINE] Available at: http://www.etsy.com/blog/news/2013/notes-from-chad-10/ [Accessed 11 Dec. 2013] 2013.

16. Hart, J., Ridley, C., Taher, F., Sas, C., Dix, A. "Exploring the facebook experience: A new approach to usability," 5th Nordic Conference on HumanComputer Interaction: Building Bridges, pp. 471-474. 2008.

17. Malinen, S. and Ojala, J. "Applying the heuristic evaluation method in the evaluation of social aspects of an exercise community," in Proceedings of the Conference on Designing Pleasurable Products and Interfaces, pp. 15. 2011.

18. Araujo, R., Santoro, F., and Borges, M. "The CSCW lab for groupware evaluation.” In Proceedings of CRIWG'02. 2002.

19. Antunes, P. Herskovic, V. Ochoa, S. F. and Pino, J. A. "Structuring dimensions for collaborative systems evaluation," ACM Computing Surveys (CSUR), vol. 44, pp. 8, 2012.

20. Patton, M. Q. "Qualitative Research and Evaluation Methods." Sage Publications, Inc. 2002.

21. Abdelnour-Nocera, J. "Ethnography and hermeneutics in cybercultural research accessing IRC virtual communities." 2002.

22. Nielsen, J. "Usability inspection methods." In Proceedings of the Conference on Human Factors in Computing Systems, 413-414." 1994.

23. Preece, J. "Sociability and usability in online communities: determining and measuring success," Behaviour \& Information Technology, vol. 20, pp. 347356, 2001.

24. Kanter, L. and Rosenbau m, S. "Usability Studies of WWW Sites: Heuristic Evaluation vs. Laboratory Testing," 1997.

25. Kim, A.J. "Community Building on the Web." Peachpit Press, Berkeley, CA. 2000.

26. Boellstorff, T., Nardi, B. Pearce, C. and Taylor, T.L. "Ethnography and Virtual Worlds: A Handbook of Method." Princeton: Princeton University Press. 2012.

27. Iriberri, A. and Leroy, G. "A life-cycle perspective on online community success." ACM Computing Surveys (CSUR), vol. 41, pp. 11, 2009. 
28. Väänänen-Vainio-Mattila, K. Wäljas, M. Ojala, J. and Segerståhl, K. "Identifying drivers and hindrances of social user experience in web services," in Proceedings of the SIGCHI Conference on Human Factors in Computing Systems, pp. 2499-2502. 2010.

29. Wellman, B. "Community: From neighbourhood to network." ACM 48, 10, 53-55." 2005.

30. Blanchard, A. L. and Markus,M. L. "The experienced "sense" of a virtual community: Characteristics and processes." Data Base Adv. Inform. Syst. 35, 1, 65-79." 2004.

31. Ridings, C. M. and Gefen, D. "Virtual community attraction: Why people hang out online." J. Comput. Mediat. Commun. 10, 1." 2004.

32. Millen,D. R., Fontaine,M. A., and Muller,M. J., "Understanding the benefit and costs of communities of practice." ACM 45, 4, 69-73." 2002.

33. Hampton, K. N. "Grieving for a lost network: Collective action in a wired suburb." Inform. Soc. 19, 417-428. 2003.

34. Leimeister, J. M., Ebner, W., and Krcmar, H. "Design, implementation, and evaluation of trust supporting components in virtual communities for patients.” J. Manage. Inform. Syst. 21, 4, 101-135. 2005.

35. Kollock, P. "Design principles for online communities." In Proceedings of the Harvard Conference on the Internet and Society. 1996.

36. Hummel, J. and Lechner, U., "Social profiles of virtual communities." IEEE Computer Society Press, Los Alamitos, CA. 2002.

37. Zhang, Y. and Hiltz, S. R. "Factors that influence online relationship development in a knowledge sharing community." In Proceedings of the Ninth Americas Conference on Information Systems (Tampa, FL, August), D. Galleta and J. Ross, Eds. AIS, Atlanta, GA. 2003.

38. Sabater, J. and Sierra, C. "Regret: A reputation model for gregarious societies," in Fourth Workshop on Deception Fraud and Trust in Agent Societies, 2001.

39. Tedjamulia, S. J. J., Olsen, D. R., Dean, D. L., and Albrecht, C. C. "Motivating content contributions to online communities: Towards a more comprehensive theory." IEEE Computer Society Press, Los Alamitos, CA. 2005.

40. Malinen, S. "Heuristics for supporting social interaction in online communities." In Proceedings of IADIS International Conference WWW/INTERNET, November 19-22, Rome, Italy, pp. 327-334. 2009.

41. Hart, J., Ridley, C., Taher, F., Sas, C., Dix, A. "Exploring the facebook experience: A new approach to usability," in Proceedings of the 5th Nordic Conference on HCI: Building Bridges, pp. 471-474. 2008.

42. Andrews, D. C., Preece, J., and Turoff,M. "A conceptual framework for demographic groups resistant to online community interaction." IEEE Computer Society Press, Los Alamitos, CA. 2001.

43. Wang, Y. and Fesenmaier, D. "Towards understanding member's general participation and active contribution to an online travel community." Tour. Manage. 25, 709-722. 2004.

44. Preece, J. "Online Communities: Designing Usability, Supporting Sociability." Wiley, New York, NY. 2000. 
45. Phang, C. W., Kankanhalli, A. and Sabherwal, R. "Usability and Sociability in Online Communities: A Comparative Study of Knowledge Seeking and Contribution." Journal of the Association forInformation Systems (10:10), pp 721-747. 2009.

46. Maloney-Krichmar, D. and Preece, J., "A multilevel analysis of sociability, usability, and community dynamics in an online health community." ACM Trans. Comput.-Hum. Interaction 12, 2, 201-232. 2005.

47. Malinen, S. and Ojala, J. "Applying the heuristic evaluation method in the evaluation of social aspects of an exercise community," in Proceedings of the Conference on Designing Pleasurable Products and Interfaces, pp. 15. 2011.

48. Preece, J., Maloney-Krichmar, D., \& Abras, C., "History and emergence of online communities." Encyclopedia of Community: From Village to Virtual World. Thousand Oaks: Sage Publications, 1023-1027. 2003.

49. Palmer, J. W. "Web Site Usability, Design, and Performance Metrics," Information Systems Research, (13)2, pp. 151-167." 2002.

50. Hornbæk, K. "Current Practice in Measuring Usability: Challenges to Usability Studies and Research," International Journal of Human-Computer Studies, (64)2, pp. 79-102." 2006.

51. Putnam, R. D. "Bowling Alone: The Collapse and Revival of American Community." New York: Simon \& Schuster. 2000. 